\title{
FOSTERING STUDENT'S SCIENTIFIC REASONING THROUGH 5E MODEL OF INSTRUCTION ON TENTH GRADE STUDENT OF PHYSICS CLASS IN SMAN 15 SURABAYA
}

\author{
Noly Shofiyah ${ }^{1}$ \\ Z. A. Imam Supardi ${ }^{2}$ \\ Budi Jatmiko ${ }^{3}$ \\ ${ }^{1}$ Postgraduate Student of Science Education Program Universitas Negeri Surabaya \\ ${ }^{2}$ Physics Department Mathematics and Science Faculty Universitas Negeri Surabaya \\ ${ }^{3}$ Physics Department Mathematics and Science Faculty Universitas Negeri Surabaya \\ e-mail:nolyshofiyah@gmail.com
}

\begin{abstract}
The aim of this study was to develop instructional package using $5 E$ model of instruction to foster student's scientific reasoning. The instructional package consisting of lesson plan, handout, student's worksheet, and scientific reasoning test was developed by using the four-D model. Subject of research in this study was instructional package using $5 E$ model of instruction which was tried out on tenth grade students of SMAN 15 Surabaya. The tryout was conducted by using the one-group pre-test post- test design. This study used three techniques for collecting data, namely observation, test, and questionnaire. The obtained data were processed with descriptive qualitative analysis. The findings revealed that the developed instructional package reflecting the $5 E$ model was valid to be implemented in classroom, the completion of the lesson plan was categorized excellent, and students were engaged actively in the instruction of the $5 E$ model as shown by their dominant activities namely performing experiment and discussion. The other findings showed that the $5 E$ model of instruction is effective to foster student's scientific reasoning skills and students gave positive responses to the implementation of the developed instructional package. However, there were obstacles that teacher and students faced during instructional process. Regarding to the findings, then it can be concluded that the developed instructional package reflecting 5 E model of instruction is effective to be implemented to foster student's scientific reasoning.
\end{abstract}

Keywords: Scientific reasoning skills, 5E model of instruction

\section{INTRODUCTION}

Physics as a science branch is the scientific study of matter and energy and how they interact with each other. Through learning physics, students are expected to be able to develop reasoning abilities in both deductive and inductive analysis, explain natural events of physics, and solve problems both qualitatively and quantitatively by using concepts and principles of physics, (Depdiknas, 2006). Scientific reasoning skill is one of the 21 st century skills expected to be taught in science classes in order toprepare students to succeed facing the challenges of globalization, (Duschl, Schweingruber, \& Shouse, 2007). Such skills are also one of several skills which are evaluated in the international tests such as PISA, (OECD,2009).

According to Karplus, et al (1977), scientific reasoning has two patterns, namely concrete reasoning pattern and formal reasoning pattern. The examples of concrete reasoning pattern are class inclusion, conservation, serial ordering, and reversibility. While the formal reasoning pattern includes theoretical reasoning, combinatorial reasoning, functionality and proportional reasoning, control variables, and probabilistic and correlational reasoning. For this study, scientific reasoning is defined as the cognitive skills of students in five dimensions including serial ordering reasoning (Arranging a set of data), theoretical reasoning (Applying theory to interpret data), functionality reasoning (Analysing functional relationship), c ontrol variables (Controlling variables), and probabilistic reasoning (Predicting based on data).

Even though scientific reasoning skills are needed in learning science, they still do not get much attention by teachers, especially the teachers at SMA Negeri 15 Surabaya. This fact was supported by the results of preliminary test of scientific reasoning administered to eleventh grade students of SMA Negeri 15 Surabaya. The gained average score of 38.7 showed that scientific reasoning skill of the students in SMAN 15 Surabaya is considered low which means that scientific reasoning skills has never been practiced by the teachers to the students. The lack of students' scientific reasoning also can be seen from the result of PISA in 2009. Indonesia, especially on the science scale, gained scores of 383 which is considered low if it is compared to the average score established by OECD about 501, (OECD, 2009). The PISA 
results describes the scientific reasoning skills of Indonesian students because the questions in the PISA test was designed to evaluate how well students apply scientific way of thinking to situations they could encounter in their daily life.

Due to such reasons, therefore, the scientific reasoning skills should be included in the learning process of science. The teachers then are expected to select an instructional model that can promote students' scientific reasoning. One of the instructional models considered to be able to facilitate the teacher in promoting students' cientific reasoning is the $5 \mathrm{E}$ Model of Instruction developed by Rodger Bybee in 1997.

The 5E model was developed by Bybee who was a leader of Biological Science Curriculum Study (BSCS). It builds on the learning cycle model. The learning cycle developed in 1960s by Robert Karplus (Karplus \& Thier, 1974) as one model reflecting inquiry instruction in science. There are five teaching phases of the 5E model, namely engage, explore, explain, elaborate, and evaluate. In the engagement phase, the teacher engages students in a new concept using short activities or questions to promote their curiosity and draw out their prior knowledge. Exploration phase leads students not only conduct activities, such as lab activities, group discussion, by means of their own preexisting knowledge, but also explore questions and implement a preliminary investigation. In the explanation phase, teacher has an opportunity to directly introduce a concept, process, or skill so that students imply whether their understanding of the concept is correct or incorrect knowledge. Meanwhile, elaboration phase allows students to advance their newly structured knowledge into a deeper and broader understanding in order to elaborate on their conceptual understanding and skills. Moreover, the students' comprehension and abilities are assessed in the evaluation phase of the $5 \mathrm{E}$, and thereby, the teacher is able to monitor how his/her students have progresses in accomplishing the learning objectives.

Many past studies in the field of 5E Model of Instruction reported that such model is very beneficial in learning science. Ergin, et al (2008) revealed that students who were in the experimental group in which the $5 \mathrm{E}$ Model had been applied were more successful in terms of achievement and attitudes towards the subject than the control group students on which traditional method had been applied. The similar study of 5E Model was performed in Tukey by Acisli, Yalcin and Turgut (2011) also explained that the results of achievement test on experimental group in which the $5 \mathrm{E}$ model is implemented showed much greater than the control group which used traditional method. From the research conducted by Metin (2011), it was found that students had many misconceptions about 'acid and bases' and the teaching instruction based on the 5E Model was concluded to be quite effective solving students' misconceptions.

This present study focuses on whether the $5 \mathrm{E}$ model of instruction can foster students' scientific reasoning. Several empirical evidences stated that the $5 \mathrm{E}$ model is effective to developed scientific reasoning of student. For instance, Johnson and Lawson (1998) identified that students who are in class using an inquiry-based approach have better prediction in achievement test than students who are in expository class. Lawson et al (2000) also added that the use of an inquiry-based approach also increased reasoning abilities of students after the course of the semester. It is in line with statement proposed by Dolan and Grady (2009) that teaching by inquiry is touted for its potential to encourage students to reason scientifically. Research reports from institutions such as the National Research Centre also supported the effectiveness of the $5 \mathrm{E}$ model in developing scientific reasoning skills (Bybee, et al, 2006). A similar result was also shown in a quantitative research conducted by Wilson et al (2009) stating that students in a class that was instructed based on the $5 \mathrm{E}$ model reached significantly higher levels of achievement compared with other class in terms of three different learning goals, namely knowledge, scientific reasoning, and argumentation.

Based on the overview stated before, then it can be concluded the development of instructional package using 5E Model of instruction is supposed to be effective in fostering students' scientific reasoning.

\section{METHODS}

This current research could be categorized as developmental research since it was aimed at developing instructional package using $5 \mathrm{E}$ model of instruction to foster scientific reasoning of students. The instructional package consisting of lesson plan, handout, student's worksheet, and scientific reasoning test was developed by using the four-D model (4D model) that consist of four stages, namely Define, Design, Develop, and Disseminate, (Thiagarajan et al., 1974). However, this study involved only three of four stages of the four-D model, since the developed instructional package was not distributed to other schools.

Research subject of this study was instructional package using 5E model of instruction which was tried out on tenth grade students of SMAN 15 Surabaya. Tryout was conducted by using the one-group pre-test post-test design, (Fraenkel, Wallen \& Hyun, 2012). Carrying out pre tests $(\mathrm{O} 1)$ before the implementation of the $5 \mathrm{E}$ model $(\mathrm{X})$, and then performing post test $(\mathrm{O} 2)$. 
The design of this study can be described as follows:

\section{O1 X 02}

Description:

$\mathrm{O} 1=$ pre-test

$\mathrm{O} 2$ = post-test

$\mathrm{X}=$ the implementation of the $5 \mathrm{E}$ model of instruction.

In this study, the developed instructional package was applied in the three different classrooms or it was replicated three times to verify that the improvement of student's scientific reasoning skill was due to the implementation of the $5 \mathrm{E}$ model.

Variables observed in this study are (1) The validity of lesson plan, handout, student's worksheet, and scientific reasoning test (2) handout readability (3) variables related to completion of lesson plan, students' activities, students' responses and students' scientific reasoning skills.

\section{RESULTS AND DISCUSSION}

Before implementation, the developed instructional package including lesson plan, handout, student's worksheet and scientific reasoning test is validated by two experts. The results showed that the developed lesson plan was considered good, handout was excellent, student's worksheet was good, and the scientific reasoning test overall was considered valid to be implemented in the classroom.

For handout, there was a test to evaluate the comprehension difficulty of handout by using cloze readability procedure. Based on the results of handout readability test, the students could respond such test about $77 \%$ indicating that the developed handout was appropriate to be implemented in the instruction. It fits with the statement which is proposed by Bormuth (1967), a passage is said to be suitable for use in student's instruction if he responds correctly to $75 \%$ or more of the questions asked to him, about the passage.

The developed instructional package that has been considered valid was then tried out in classroom to know its effectiveness. The tryout in this study was conducted in SMAN 15 Surabaya to gather data about completion of lesson plan, student's activities, students' responses and students' scientific reasoning skills.

\section{A. Completion of Lesson Plan}

The instructional activities by the teacher reflecting $5 \mathrm{E}$ model of instruction were observed by two observers in terms four aspects, namely preparation, implementation, time management, and learning environment. The lesson plan was designed based on the phases of the $5 \mathrm{E}$ model involving engage, explore, explain, elaborate, and evaluate. The observation results showed that completion of lesson plan was categorized excellent with the reliability score of two observers of $95 \%$.

Slavin (2006) stated that to be effective instruction, the instruction should consider four elements and one of them is quality of instruction. Quality of instruction is the degree to which the instruction can help students easily mastery of the knowledge or skill taught. Such statement fits with the findings of this study that the instruction, that was $5 \mathrm{E}$ model of instruction, could assist students to learn one dimensional motion topic and scientific reasoning skills. This was supported by the results of the scientific reasoning test in which the average score of test before and after the implementation of 5E model of instruction respectively is 8.9 and 74.6 .

\section{B. Students' Activities}

Students' activities in terms of reading and collecting information from the handout, discussing, listening to teacher's explanation, taking note, doing experiment, asking, posing ideas, and irrelevant activities were observed in each meeting by two observers. Regarding to the observation results, the dominant activity performed by the students in classroom was experimental activities about $23.7 \%$. It was in line with the scenario that was planned in which students should build their conceptual understanding through experimental processes such as posing hypothesis of experiment, controlling variables of experiment, constructing measurement methods, analysing the data and making conclusion.

The second dominant activity was the discussion about $20.3 \%$. This happened since every phase in $5 \mathrm{E}$ model encouraged discussion among students and between teacher and students. As Arends (2009) contended that discussion in inquiry instruction is used to engage students in higher order thinking and thereby, to encourage their own intellectual investigation. In the discussion, students were also encouraged to ask, share ideas and opinions. Such activities could be seen in this instruction, in which $10.5 \%$ of students pose questions and $16.0 \%$ of students propose their ideas and opinions.

\section{Students' Responses}

From the questionnaire of students' responses of the 5E model implementation, it was obtained information that the students responded content, handout, student's worksheet and instructional process are interesting, recent, and understandable. They also agree if the 5E model to be implemented on their next physics lessons. The positive responses of students indicated that students were enthusiastic and motivated to follow instructional process reflecting the $5 \mathrm{E}$ model. In other words, the $5 \mathrm{E}$ model of 
instruction is one of the teaching models that can motivate students to learn. This fact was also supported by the observation results of completion of lesson plan in this present study and the study made by Boddy, Watson and Aubusson (2003) arguing that a unit study in primary school 3rd grade based on 5E model was found to be interesting and funny by students.

\section{Scientific Reasoning Test}

The obtained data from scientific reasoning test of X-7, X-8 and X-9 students in SMAN 15 Surabaya were then processed using a standard data analysis techniques that is the $\mathrm{N}$-gain score $(<\mathrm{g}>)$. Such analysis was used to investigate whether $5 \mathrm{E}$ model of instruction can effectively foster student's scientific reasoning skills in SMAN 15 Surabaya.

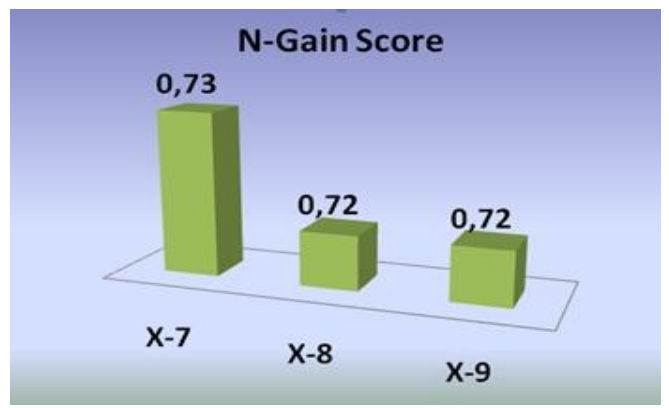

\section{Figure 3.1 N-Gain Score of Student's Scientific Reasoning}

Figure 3.1 showed that all of the average N-gain scores are categorized as a high-g level which means that the implementation of the $5 \mathrm{E}$ model in the classroom has a great effect to the improvement of students' scientific reasoning skills.

The fact that the $5 \mathrm{E}$ model of instruction was able to foster students' scientific reasoning skills can be explained for three reasons. Firstly, through using $5 \mathrm{E}$ model of instruction, hypothesis, determining and defining variales, completing procedures, collecting data, discussing data analysis and generating conclusion in which all of such skills are scientific reasoning skills that should be mastered by the students. Secondly, in the explanation phase of $5 \mathrm{E}$ model of instruction, students were asked to present and explain what they have found and noticed during the exploration phase and reflect on their results. Consequently, the students were encouraged to defend their ideas and opinions and reason scientifically in front of their friends. Lastly, the $5 \mathrm{E}$ model of instruction provided opportunities to students to construct new understanding by applying their acquired knowledge or skill to new situation so that they will get a deeper understanding.

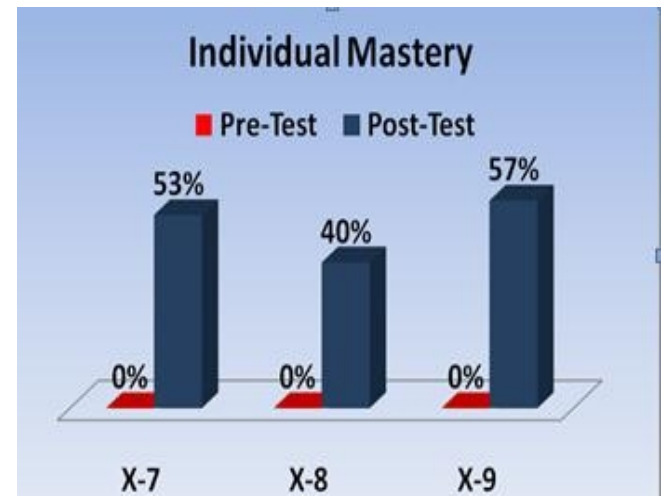

Figure 3.2 Individual Mastery of Scientific Reasoning of One Dimensional Motion Topic

Furthermore, if the results of scientific reasoning test were compared to the individual mastery standard of SMAN 15 Surabaya, that is 75, the students' mastery of one dimensional motion topic in each class could be categorized moderate. Arguably, this happened since the students did not gain the maximum score in each item of scientific reasoning test. The students were able to identify some variables influencing the experiment but they cannot explain the reason for choosing the variables. The students were able to respond difficult problem by applying a related theory, but not necessarily complete reasons. In other words, students in SMAN 15 Surabaya were in concrete reasoning pattern. According to Karplus, et al, (1997), the individuals who are in concrete reasoning patterns, are not aware of their own reasoning, inconsistence among various statements, or contradictions with other known facts.

\section{CONCLUSION}

In conclusion, based on the results and discussion that have been presented above, the developed instructional package reflecting $5 \mathrm{E}$ model of instruction consisting of lesson plan, handout, student's worksheet, and scientific reasoning test is effective to be implemented to foster student's scientific reasoning.

\section{ACKNOWLEDGMENT}

I would like to express my sincere gratitude and appreciation to Prof. Dr. Budi Jatmiko, M.Pd as supervisor and Dr. Z. A. Imam Supardi, M.S as co- supervisor for their support, guidance, and help to complete this paper. To Prof. Suparman Kardi, M.Phil, Ph.D for being evaluator of instructional package. I appreciate their time and suggestions for improving my instructional package. 


\section{REFERENCES}

Acisli, S., Yalcin, S. A., \& Turgut, U. (2011). Effects of the 5E learning model on students' academic achievements in movement and force issues. Procedia Social and Behavioral Sciences, 15, 2459-2462.

Arends, R. I. (2009). Learning to teach. New York: McGraw-Hill.

Boddy, N., Watson, K., \& Aubusson, P. (2003). A trial of the five es: a referent model for constructivist teaching and learning. Research in Science Education, Kluwer Academic Publisher. Printed in the Netherland, 33, 27-42.

Bybee, R. W., Taylor, J.A., Gardner A., Scotter, P. V., Powell, J.C., Westbrook, A. \& andes, N. (2006). The bscs 5e instructional model: origins and effectiveness. Office Of Science Education National Institutes Of Health. 1-80.

Depdiknas. (2006). Kurikulum Tingkat Satuan Pendidikan. Jakarta: Balai Pustaka.

Dolan, E. \& Grady, J. (2009). Recognizing Students' Scientific Reasoning: A Tool for Categorizing Complexity of Reasoning During Teaching by Inquiry. Journal Science Teacher Education. 21, 31 55.

Duschl, R. A., Schweingruber, H. A., \& Shouse, A. W. (2007). Taking Science to School: Learning and Teaching Science in Grades K-8. Washington, D.C.: The National Academies Press.

Ergin, I. (2008). An example for the effect of 5E Model on the academic success and attitudes levels of students: Inclined projectile motion. Journal of Turkish Science Education. 5(3), 47-59.

Fraenkel, J. R. Wallen, N. E \& Hyun, H. H. (2011). How to Design and Evaluate Research in Education 8th Ed. Mc GrawHill: United State.

Johnson, M. A., \& Lawson, A. E. (1998). What are the relative effects of reasoningability and prior knowledge on biology achievement in expository and inquiry classes? Journal of Research in Science Teaching, 35(1), 89-103.

Karplus, R., \& Thier, H. (1974). SCIS teacher's handbook. Berkeler, CA: Science Curriculum Improvement Study.

Karplus, R., et al., (1977). Science teaching and the development of reasoning. Journal of Research in Science Teaching, 14(2), 169-175.

Lawson, A. E., Alkhoury, S., Benford, R., Clark, B. R., \& Falconer, K. A. (2000). What kinds of scientific concepts exist? Concept construction and intellectual development in college biology. Journal of Research in Science Teaching, 37(9), 996-1018.

Metin, M. (2011). Effects of teaching material based 5E
Model removed pre-service teachers' misconceptions about acids-bases. Bulgarian journal of Science and Education Policy. 5(2), 274-302.

OECD. (2009). Take the Test: Sample Questions from Oecd's Pisa Assessments -ISBN 978-92-64-05080-8.

Slavin, R. E. (2006). Educational Psychology: Teory and Practice 8th ed. Boston: Pearson.

Thiagarajan, et al. (1974). Instructional Development for Training of Exceptional Children a Sourcebook. Bloomington: Center for Innovation on the Teaching the Handicaped.

Wilson, C., Taylor, J., Kowalski, S., and Carlson, J. (2009). The relative effects of inquiry based and commonplace science teaching on students' knowledge, reasoning and argumentation. Journal of Research in Science Teaching (accepted for publication Juli 2009). Available: http://www3.interscience.wiley.com/cgiin/fulltext/122 686765/PDFSTART[retrieved January 2010]. 